\title{
El tipo nomenclatural de Tragopogon dalechampii L. (Compositae)
}

\author{
Pedro Pablo Ferrer-Gallego ${ }^{1,2}$, Emilio Laguna ${ }^{1} \&$ Salvador Talavera $^{3}$ \\ 1 Servicio de Vida Silvestre. Centro para la Investigación y Experimentación Forestal (CIEF). Generalitat Valenciana. Av. \\ Comarques del País Valencià, 114, E-46930, Quart de Poblet, Valencia. \\ 2 VAERSA. Marià Cuber, 17, E-46011, València, España \\ 3 Departamento de Biología Vegetal y Ecología, Universidad de Sevilla, E-41080, Sevilla, España.
}

\section{Resumen}

Correspondencia

P.P. Ferrer-Gallego

E-mail: flora.cief@gva.es

Recibido: 30 junio 2013

Aceptado: 16 julio 2013

Publicado on-line: 22 julio 2013

Se designa como lectótipo del nombre Tragopogon dalechampii L. (Compositae) un ejemplar conservado en el herbario LINN.

Palabras clave: Compositae, lectótipo, Linneo, nomenclatura, Tragopogon.

\begin{abstract}
Nomenclatural type of Tragopogon dalechampii L. (Compositae)

The lectotype of Tragopogon dalechampii L. (Compositae) is designated from original material conserved in Herbarium LINN.
\end{abstract}

Key words: Compositae, lectotype, Linnaeus, nomenclature, Tragopogon.

\section{Introducción}

En la actualidad la planta linneana Tragopogon dalechampii se incluye dentro del género Urospermum Scop., nom. cons. prop. [Tragopogonoides Vaill., nom. rej. prop.] (Compositae). El género contiene solo 2 especies [U. dalechampii (L.) Scop. ex F.W. Schmidt y U. picroides (L.) Scop. ex F.W. Schmidt] repartidas por el centro y sur de Europa, norte de África y oeste de Asia hasta Irán y Pakistán (Lack \& Leuenberger, 1979), aunque $U$. picroides ha sido introducida en otros territorios del planeta.

En concreto, U. dalechampii es un hemicriptófito erecto o ascendente y algo robusto, hasta de $40 \mathrm{~cm}$ de altura, con hojas inferiores profundamente divididas en segmentos triangulares, siendo el apical mayor y algo redondeado, las caulinares aparecen sentadas y poco o nada divididas, las superiores opuestas o subopuestas, incluso en verticilos de tres; los capítulos son solitarios al final de un largo pedúnculo que se engruesa en su ápice en la fructificación; las brácteas del involucro son anchamente lanceoladas $\mathrm{y} \pm$ obtusas; $\mathrm{y}$ los aquenios con el cuerpo transversalmente rugoso. Esta especie se distribuye por el Mediterráneo occidental, habitando en pastizales sobre suelos algo profundos o húmedos de zonas no muy alejadas del litoral.

Desde el punto de vista nomenclatural, para este nombre todavía no se ha propuesto su correspondiente tipo (Jarvis, 2007). El presente trabajo trata la tipificación de Tragopogon dalechampii L., a partir de la consulta del material original de Linneo y la bibliografía citada en el respectivo protólogo.

\section{Tipificación}

Tragopogon dalechampii L., Sp. Pl.: 790 (1753)

$\equiv$ Urospermum dalechampii (L.) Scop. ex F. W. Schmidt in Samml. Phys.-Oekon. Aufsatze 1: 276 (1795)

Ind. loc.: "Habitat in Hispania"

Typus: Lectotypus (hic designatus): Herb. Linn No. 946.6 (LINN) (http://linnean-online.org/ 9556/\#). 


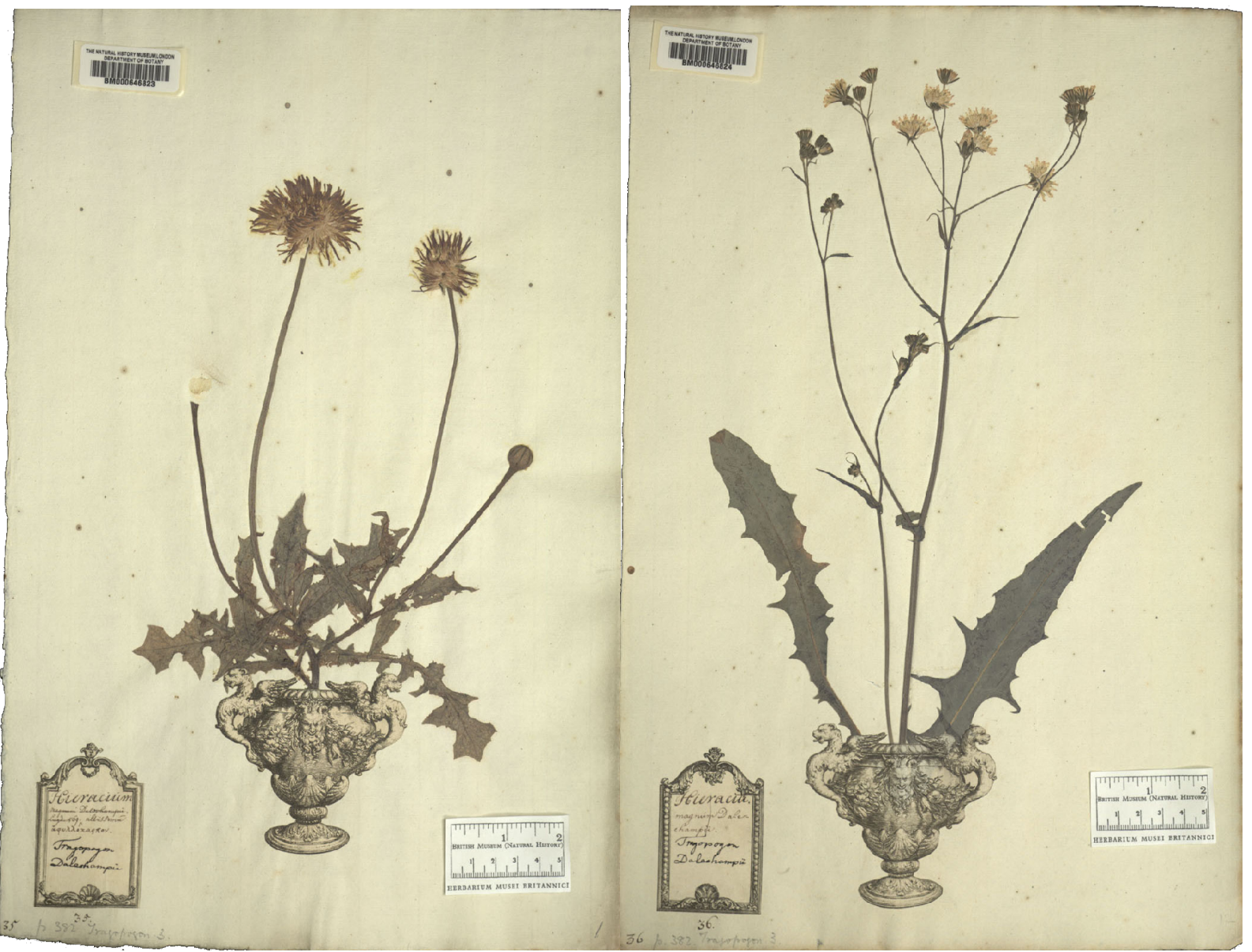

Figura 1.Material original de Tragopogon dalechampii conservado en el herbario BM (Herb. Clifford: 382, Tragopogon 3 [BM 000646823 ] y [BM 000646824]). Herbario BM, reproducido con permiso.

Figure 1.Original material of Tragopogon dalechampii conserved in Herbarium BM (Herb. Clifford: 382, Tragopogon 3 [BM 000646823] and [BM 000646824]). Herbarium BM, reproduced with their permission

La nomina legitima specifica "Tragopogon calycibus corolla brevioribus inermibus" la toma Linneo (1753: 790) directamente de dos obras anteriores, Hortus Upsaliensis (Linneo, 1748: 244) y Hortus Cliffortianus (Linneo, 1738: 382). En Hortus Cliffortianus, Linneo hace una descripción detallada de la planta "Radix perennis; caulis ramosus; folia oblonga, pinnato-hastata, extima vix majori lacinia, parum villosa; pedunculi terminatrices, longissimis, nudi; Capitula solitaria, globosa primum \& pubescentia, dehiscente tandem calyce in octo partes aequales ultra médium."

Jarvis (2007: 892) indica como posibles tipos de $T$. dalechampii los materiales que se encuentran en los pliegos 382 Tragopogon 3 (2 pliegos) del Herbario de Clifford, en el pliego 946.6 del Herbario de la Sociedad Linneana de Londres (LINN), y en el icono "Chondrilla prior dioscoridis legitima" de Clusius (1601: CXLIII). Pero Linneo, en el Hortus Cliffortianus, indica además el icono "Chondrilla foliis cichorii tomentosis" de Morison (1699: 72), que también se podría elegir como tipo (iconotipo).

De todos los posibles tipos, el del herbario de la Sociedad Linneana de Londres (LINN n ${ }^{\circ}$ 946.6) es el mejor candidato. Contiene una planta de unos $30 \mathrm{~cm}$, con dos ramas monocéfalas, y todas las hojas en el tercio inferior, las más superiores opuestas o subopuestas, la rama principal con el capítulo en fructificación, y la secundaria con el capítulo en floración; las brácteas del involucro del capítulo maduro son seríceas, carentes de pelos setáceos. En la base del pliego, con letra del propio Linneo, figura el doble código " 6 dalechampii" con el que Linneo reconoció sus especies descritas en la primera edición de Species Plantarum de 1753 , por lo que no hay duda que esta planta fue tenida en cuenta por Linneo cuando describió $T$. dalechampii, cuyos caracteres se ajustan a la descripción que hace en el Hortus 


\section{Cliffortianus.}

Los otros posibles tipos antes aludidos, los dos pliegos que se encuentran en el Herbario de Clifford (BM), el 382, Tragopogon 3 (BM $000646823)$ se identifica con $U$. dalechampii o con un híbrido de $U$. dalechampii con $U$. picroides, y el 382, Tragopogon 3(2) (BM 000646824) se identifica con una especie de Crepis, posiblemente C. capillaris (Fig. 1).

En conclusión, tanto los iconos de Clusius (1601: cxliii) y Morison (1699: tab. VII, sect. VII, fig. 1), como los ejemplares que contienen los pliegos Herb. Clifford: 382, Tragopogon 3 (BM 000646823) y Herb. Linn No. 946.6 (LINN), son materiales sobre los que poder designar el tipo del nombre Tragopogon dalechampii L. Se ha elegido como lectótipo el ejemplar del pliego No. 946.6 del herbario de la Sociedad Linneana de Londres (LINN), por ser el único elemento donde se tiene constancia que fue utilizado por Linneo cuando describió la especie, plenamente coincidente con la descripción que se encuentra en el Hortus Cliffortianus.

\section{Agradecimientos}

Los autores agradecen al Dr. M. Spencer por en- viarnos las imágenes digitalizadas del material original de Tragopogon dalechampii conservado en el Herbario de Clifford 382, Tragopogon 382, depositado en el Museo Británico (BM), y al Natural History Museum por permitir su reproducción. Este trabajo fue financiado con fondos FEDER, del Ministerio de ciencia e Innovación de España (CGL2009-08178 y CGL2012-32914; IP: S. Talavera).

\section{Referencias}

Clusius, C. 1601. Rariorum plantarum Historia, et Appendix ad Historiam plantarum. Ed. Christophoro Plantini. Antwepen.

Jarvis, C. 2007. Order out of chaos: Linnaean plant names and their types. Linnean Society of London and the Natural History Museum, London.

Lack, HW, \& Leuenberger B. 1979. Pollen and taxonomy of Urospermum (Asteraceae, Lactuceae). Pollen and Spores 21: 415-425.

Linneo, C. 1738. Hortus Cliffortianus. Amsterdam.

Linneo, C. 1748. Hortus Upsaliensis. Stockholm. Impensis Laurentii Salvii.

Linneo, C. 1753. Species Plantarum. Stockholm.

Morison, R. 1699. Plantarum Historiae Universalis Oxoniensis pars secunda [tertia] seu Herbarum Distributio Nova, per tabulas cognationis \& affinitatis Ex Libro Naturae Observata \& Detecta. Oxonii [Oxford], e Theathro Sheldoniano. 